\title{
A MOTIVAÇÃO DOS ALUNOS NOS CURSOS DE CAPACITAÇÃO PROFISSIONALIZANTE VISANDO UMA APRENDIZAGEM PLENA E MUDANÇA DE POSTURA
}

\author{
Adriana Croti, Carmen Lúcia Dias
}

Discente do mestrado em Educação - UNOESTE. Docente do mestrado em Educação da UNOESTE. E-mail: adrianacroti@hotmail.com

\section{RESUMO}

O inicio dos anos 80 é o marco das pesquisas sobre motivação escolar, e estas perduram até hoje. Autores como Maslow, Piaget, Ausubel, McClelland e outros debruçaram sobre esta questão trazendo contribuições aplicadas atualmente. A partir da leitura de pesquisadores que trabalham essa temática, esse artigo aborda aspectos da aprendizagem, motivação, suas questões cognitivas, afetivas e a relação com o atual mercado de trabalho. O investimento do Governo Federal por meio do Programa Nacional de Acesso ao Ensino Técnico e Profissionalizante, focado na área de capacitação de alunos para inclusão no mercado de trabalho expôs a relação aluno, educação de base, educação profissional e o mercado de trabalho. Manter estes alunos interessados na aprendizagem profissional e, também, no aprimoramento do conhecimento para o seu desenvolvimento profissional passa pelo processo motivacional e por uma metodologia de ensino que exerça este papel e que garanta uma aprendizagem plena e mudança de postura.

Palavras-chave: motivação, mercado de trabalho, aprendizagem.

\section{INTRODUÇÃO}

O desenvolvimento econômico-social e a globalização provocaram alterações no mercado de trabalho brasileiro nos últimos anos. O Brasil vive um momento de pleno emprego, com o índice de desocupação abaixo de 6\%, segundo o Instituto Brasileiro de Geografia Estatística - IBGE, através do site (BRASIL, 2013), o que tem gerado dificuldades para a contratação de mão-de-obra capacitada. Na contramão, uma massa de desempregados e subempregados busca uma oportunidade que proporcione a inclusão, ou a promoção, neste mercado extremamente disputado. Entretanto, há uma deficiência na educação de base, em especial na leitura e interpretação de texto.

O Sistema de Avaliação da Educação Básica - SAEB, do Ministério da Educação, revela que das séries avaliadas entre o 50 e 9o ano do Ensino Fundamental e o 3 o ano do Ensino Médio apenas 35\% dos alunos possuem aprendizado adequado, seja em língua portuguesa ou em matemática, de acordo com pesquisa apresentada pelo Ministério da Educação (BRASIL, 2013).

Isto gera uma espécie de dicotomia no mercado, onde, de um lado encontram-se as organizações em busca de pessoas já preparadas, com capacidade de tomada de decisões e 
discernimento, e do outro lado, pessoas não preparadas, que possuem como alternativa buscar cursos de capacitação profissional.

A procura por estes cursos tem apresentado crescimento junto às instituições do Sistema "S", sob o estimulo do Programa Nacional de Acesso ao Ensino Técnico e Profissionalizante (PRONATEC), criado pelo Governo Federal, com a condição peculiar de atender um público com formação no nível fundamental. com vistas a suprir demandas que decorrerão da Copa do Mundo em 2014 e das Olimpíadas em 2016. Estes cursos capacitam, aperfeiçoam e atualizam o aluno que tem urgência em ingressar no mercado de trabalho, desenvolvendo as competências necessárias para que ele desempenhe uma ocupação; são cursos com 190 horas aproximadamente, para as diversas áreas como: Operador de Computador, Auxiliar Administrativo, Recepcionistas, Técnico em Enfermagem, Técnico em Administração e Técnico e Segurança no Trabalho, conforme a Revista do Serviço Nacional de Aprendizagem Comercial - Senac (REVISTA DO SENAC, 2013, p. 7).

Manter estes alunos interessados na aprendizagem profissional e, também, no aprimoramento do conhecimento para o seu desenvolvimento profissional passa pelo processo motivacional e pela elaboração de uma didática de ensino que exerça este papel.

\section{A FORÇA DA MOTIVAÇÃO}

A motivação está no foco de estudos desde os anos 80. Atualmente, observa-se uma mudança qualitativa nestes estudos e com enfoques cognitivistas. A motivação, no contexto escolar, se revela como resultado de sua construção histórica, como um objeto complexo, uma vez que são vários fatores, sejam pessoais e externos que a provocam.

Motivação vem do verbo latino movere, deram origem ao nosso termo semanticamente aproximado, que é motivo. Assim, genericamente, a motivação ou o motivo, é aquilo que move uma pessoa ou que a põe em ação ou faz mudar o curso. A motivação tem sido entendida ora como um fator psicológico, ou um conjunto de fatore, ora como um processo. Existe um consenso generalizado entre os autores quanto à dinâmica desses fatores psicológicos ou de processo em qualquer atividade humana. (BORUCHOVITCH, E; BZUNECK, J. 2001, p.9).

É sabido que a motivação é um somatório do processo emocional e do cognitivo, que induz e provoca o início de um comportamento direcionado a determinado objetivo. Surge por meio do discernimento pessoal e assegura a persistência no alcance daquele objetivo, mesmo diante do aparecimento de fatores que possam interromper a atividade. 
Com o passar do tempo e por conta de diferentes aplicabilidades o termo motivação recebeu outras definições complementares, ligadas a metas pessoais. Mas para Burochovitch e Bzunech (2001), o contexto específico da sala de aula e as atividades realizadas pelo aluno possuem características peculiares que as diferenciam de outras como o lazer, o esporte ou o trabalho. O aluno deve manter a persistência e motivação para a realização de atividades quase sempre de natureza cognitiva, que incluem atenção, raciocínio, processamento, elaboração e integração da informação e resolução de problemas. A motivação do aluno está então relacionada com o trabalho mental, sendo assim, este fator o tangencia da conceituação pura da motivação humana. A motivação tem sido a preocupação dos estudiosos da área, uma vez que a queda da mesma impacta na aprendizagem.

Maeher e Meyer (1997) abordam-na com a metáfora do investimento pessoal. Observam que toda pessoa dispõe de certos recursos pessoais, que são tempo, energia, competências, conhecimentos e talentos que poderão ser investidos numa certa atividade. E acreditam que deva ser nestes aspectos que o estudo da motivação deva começar e findar. A questão não trata se as pessoas estão ou são motivadas, e sim quando e como investem seus talentos em uma atividade por determinado tempo e, se necessário, com persistência. Estar motivado na escola implica num envolvimento e investimento pessoal elevado. Considerando que o aprendizado se dará através do desenvolvimento de ações cognitivas, metacognitivas e do gerenciamento destes recursos, sua ausência representa a queda destes investimentos pessoais.

Alunos desmotivados estudam muito pouco ou nada e, consequentemente, aprendem muito pouco. Em ultima instancia, ai se configura uma situação educacional que impede a formação de indivíduos mais competentes para exercerem a cidadania e realizarem-se como pessoas, além de se capacitarem a aprender pela vida afora. (BORUCHOVITCH, E; BZUNECK, J. 2001, p.13).

Desta forma, quais atividades ou tarefas podem aumentar a vontade dos alunos se esforçarem na aprendizagem?

\section{TEORIAS DE APRENDIZAGEM E A MOTIVAÇÃO}

Para Piaget (1999), o ser humano, se encontra desde o nascimento, submerso num meio social que atua sobre ele do mesmo modo que o meio físico. E, o aluno visto como sujeito epistemológico, com capacidade de construir relações, possui habilidades que proporcionarão o conhecimento como: observar, relacionar, classificar, abstrair, separar, reconstruir, realizar 
conexões e concluir, reagindo conforme esteja interessado em obter respostas e motivado em aprender.

Ainda do autor, o individuo só age quando experimenta uma necessidade, isto é, quando surge um desequilíbrio momentâneo entre o meio e o organismo; então a ação tende a restabelecer o equilíbrio, ou seja, readaptar o organismo a esta nova situação. Observamos assim que o meio social e a escola, através de constructos curriculares definidos, transformam o aluno, e este, numa ação contrária, acaba por modificar também o meio. A eficácia dessa interação depende do quanto o aluno esteja motivado.

Para que aconteça a troca entre o meio e o organismo e se estabeleça a equilibração é importante observar dois aspectos interdependentes: o afetivo e o cognitivo. A vida afetiva e a cognitiva são inseparáveis, embora distintas. Qualquer troca com o meio supõe uma nova estruturação e uma valorização, ou seja, um ato de inteligência provoca um ajuste interno e externo.

Contribuindo, temos a Teoria de Aprendizagem Significativa de Ausubel.

Segundo Moreira (1999, p. 153)

Para Ausubel, aprendizagem significativa é um processo por meio do qual uma nova informação relaciona-se com um aspecto especificamente relevante da estrutura de conhecimento do indivíduo, ou seja, este processo envolve a interação da nova informação com uma estrutura de conhecimento específica, a qual Ausubel define como conceito subsunçor, ou simplesmente subsunçor, existente na estrutura cognitiva do indivíduo. A aprendizagem significativa ocorre quando a nova informação ancora-se em conceitos ou proposições relevantes, preexistente na estrutura cognitiva do aprendiz.

Portanto, para Ausubel, o conhecimento pré-existente influencia na aprendizagem. Aprender significativamente é ampliar e reconfigurar ideias já existentes na estrutura mental, e ter capacidade de relacionar a novos conteúdos. Quando há o encontro de um material potencialmente significativo para o aluno e este tem disposição para aprender de modo concreto surgem os fatores motivacionais.

Moreira (1999) apresenta, também, a definição de Ausubel para a aprendizagem mecânica "como sendo a aprendizagem de novas informações com pouca ou nenhuma interação com conceitos relevantes existentes na estrutura cognitiva". Ou seja, a nova informação é armazenada de forma aleatória, sem interação com outra já armazenada. Porém, a aprendizagem significativa e a mecânica não são dicotômicas, mas criam entre si um continum. A mecânica é necessária 
quando o aluno adquire novos conhecimentos, ou seja, até que alguns elementos existam na estrutura cognitiva do aluno e, aos poucos, tornem-se os subsunçores.

A decisão do aluno em realizar uma atividade escolar, segundo Boruchovicth e Bzuneck (2001) está relacionada à Teoria de Ausubel sob alguns aspectos: o aluno percebe o significado do conteúdo e faz relação com seus próprios interesses; a atividade é definida em termos de metas específicas e de curto prazo, percebendo que com determinada dedicação consegue concluir, com maior atenção para a compreensão do conteúdo e, desta forma, pode melhorar ou levá-lo a obter o conhecimento ou habilidades.

Também, a Teoria de Ausubel coloca o professor na posição de aprender a aprender a conhecer cada um de seus alunos e, conhecendo-os, ensinará de acordo. O professor torna-se mediador, auxiliando o aluno a superar dificuldades cognitivas e emocionais, tornando-o mais motivado e autônomo na construção de seu conhecimento. Nestas circunstâncias cabe ao professor conhecer as estratégias de aprendizagem e as diferentes formas de motivação: intrínseca, extrínseca e uso de recompensas.

Acrescentando, Penna (1979, p. 36) coloca que

o cérebro não funciona apenas com estímulos mas tem atividade própria. Em compensação, ele precisa de estímulos para regular sua atividade, origem biológica que talvez implique a necessidade de curiosidade.

A motivação intrínseca refere-se à atividade que desperta interesse e gera satisfação e é realizada pelo fim em si mesma. Entende-se que o aluno nesta circunstância esteja em busca do novo, da satisfação da curiosidade ou para exercitar suas habilidades. Mesmo sendo forte e persistente a motivação intrínseca pode tornar-se vulnerável às forças do ambiente. Tem forte relação com a aprendizagem, uma vez que provoca a satisfação e promove o aumento de desempenho pelo aluno (PENNA, 1979).

A motivação extrínseca no ambiente escolar refere-se a uma avaliação cognitiva das atividades como um meio dirigido a um fim. O aluno acredita que ao se envolver na tarefa terá resultados desejados como elogios, notas, prêmios e certificação.

Já o uso de recompensas em salas, pensamento abordado também por Skinner, é frequentemente utilizado na busca para se obter o envolvimento dos alunos nas atividades propostas. Mas estas estratégias foram menos eficazes para provocar o envolvimento nas atividades quando comparadas às provocadas pela motivação intrínseca. Ainda segundo Penna (1979, p. 37) "o reforço "mata" a motivação intrínseca." 
Mas observa-se a diminuição da motivação intrínseca também em outras situações como coações, evitação de punição, vigilância ou até mesmo imposição de um tempo limite. (PENNA, 1979 p. 40).

Sendo assim, não minimizando a motivação extrínseca, podemos considerar que a motivação que tem maior interferência e auxilia no processo de aprendizagem é a intrínseca, pois esta fará com que o aluno permaneça no foco da busca pelo novo, se valendo de interesse e persistência.

\section{A PROFISSIONALIZAÇÃO E A MOTIVAÇÃO}

O Programa PRONATEC capacitou através da instituição Serviço Nacional de Aprendizagem Comercial - SENAC em 2012, mais de 2,5 milhões de pessoas, sendo 788.979 nos Cursos Técnicos e 1.732.439 nos cursos de Formação Inicial Continuada (FIC), segundo a Revista do Serviço Nacional de Aprendizagem Comercial - Senac (REVISTA DO SENAC, 2013, p. 7).

Estes cursos possuem algumas características peculiares: sua própria condição de profissionalizante, a carga horária, o público, o conhecimento, e amadurecimento da personalidade e as diferentes faixas etárias. Todas estas características tornam a sala eclética. As disciplinas apresentam uma grande quantidade de novas informações, sejam técnicas, conceituais ou abstratas. Elas são distintas do ensino de base e, dependendo das experiências e vivências do aluno, o novo pode se potencializar. O conhecimento adquirido na escola de base é condição sine qua non para melhor formação do aluno. Mas, as dificuldades de compreensão e de raciocínio existentes afetam o desenvolvimento e o grau de motivação.

Mosquera (1977) apresenta fatores que são próprios dos alunos como: o fator de compreensão e capacidade de fluência verbal. O fator de facilidade nas operações matemáticas; a capacidade espacial; o fator memória; a capacidade perceptual e o fator do raciocínio. Estes fatores ligados à visão que o aluno tem de mundo será como ele elaborará suas próprias ideias, e que influenciados pelos estímulos do meio podem promover um estado de motivação.

Neste ambiente eclético como é o da sala de aula, observa-se o comportamento do adolescente. Para Piaget (1967), o adolescente devido a sua personalidade em formação coloca-se em igualdade com os mais velhos, sentindo-se outro, e não os imitando. A nova vida os agita e por isso buscam ultrapassá-los com o desejo de transformar o mundo. Quando estão em estado receptivo acolhem de modo passivo e positivo as orientações dos mais velhos, considerando-se a individualidade e o momento de cada aluno. 
Assim, as ações em sala devem considerar o afeto, a paciência, a tolerância e o interesse pelo aluno. Deve-se estabelecer uma atmosfera de interação, cooperação e de respeito; ser um espaço de socialização, onde se busca não apenas o desenvolvimento cognitivo, mas a formação de relações maduras e consistentes que, com criatividade, desenvolvam a postura profissional e revertam em motivação ao grupo.

No entanto, alcançar esta situação tem sido o maior desafio enfrentado por professores. Mesmo tendo preparado a melhor atividade aula, ainda assim, quem determina se houve ou não aprendizado é o aluno. Aprender é individual. É um processo que acontece no aluno, onde ele é agente essencial desta aprendizagem. Por isso a aula deve proporcionar a curiosidade, reflexão, assimilação e a negociação de significados buscando fazer sentido aos alunos de forma que estes possam reprogramar seus conhecimentos prévios e apresentar um crescimento em quantidade e qualidade de conhecimentos.

Não existe um aluno igual ao outro; as habilidades e competências são diferentes e afloram em tempos distintos. A troca de experiências em sala de aula, a socialização das ideias e a organização dos conteúdos a serem ministrados serão norte para o aprendizado. Nesta condição o professor deve entender o seu papel de facilitador e mediador deste processo. As formas de interação com o mundo tornam-se mais complexas à medida que o aluno se desenvolve e exige mais respostas. Por isso, o conhecimento do professor sobre os conteúdos apresentados fortalecem esta situação. Nos cursos de capacitação profissional a especialidade do professor é questão estratégica para um aprendizado mais consistente.

O aluno deve perceber que seu desenvolvimento é dinâmico e infinito. E que, esta situação ocorre tanto a escola como no ambiente de trabalho. Para conseguir um emprego, continuar trabalhando e conquistar as promoções desejadas, este aluno, hoje, deve acostumar-se a manterse interessado em aumentar sua capacidade de aprendizagem e seu estado motivacional. A motivação no processo de capacitação profissionalizante poderá proporcionar ao aluno uma maior empregabilidade. Felizmente, o conhecimento plantado germinará regado pelas ações pessoais enfrentadas por estes alunos. Por esta razão o educador deve oferecer, neste aspecto, uma aprendizagem que implique em maior qualidade em detrimento a quantidade. As novas referências ancorarão o aprendizado deste aluno quando das suas relações com outros cursos, disciplinas, atividades e meios sociais. O aprendizado não para nunca.

\section{CONSIDERAÇÕES FINAIS}


Uma ação educativa de qualidade pressupõe a geração de estímulos que proporcionem desconforto e dúvida. Por isso, a posição do professor no contexto da capacitação profissional deve ser a de estimular e motivar os alunos para quando se depararem com "situações problema", pois o desenvolvimento deve ser total, passando pelo cognitivo, relacionado às habilidades e competências, pelo emocional e valores, que culminarão em sua futura postura pessoal e profissional.

O professor especialista de sua matéria deve ser capaz de realizar o levantamento das competências de seus alunos, para elaborar um conteúdo que busque o aprender a aprender e a motivação dos alunos em sala, apesar das diversidades e disparidades que possam existir. Observando as teorias de aprendizagem e os aspectos motivacionais, o professor tem grandes chances de estabelecer a tríade - aluno, conteúdo e professor - e que esta possibilite gerar profissionais com capacidade e competência para conquistar uma posição no tão desejado mercado de trabalho.

Uma mudança efetiva na postura e aprendizagem dos alunos será consequência de quão eficaz foi sua motivação. Esta, promovida de início pelo professor através de aulas intrigantes, questionadoras e atualizadas, deve-se manter ao longo da vida profissional para que sejam constantes as oportunidades no mercado de trabalho.

\section{REFERÊNCIAS}

BORUCHOVITCH, E.; BZUNECK, J. A.(Org.) A motivação do aluno: contribuições da psicologia contemporânea. Petrópolis, Rio de Janeiro: Vozes, 2001.

BRASIL, Instituto Brasileiro de Geografia e Estatística - IBGE. Pesquisa mensal de emprego. Visualizada através de < http://www.ibge.gov.br/home/ > Acesso em: 27/06/2013.

BRASIL, Ministério da Educação - Instituto Nacional de Estudos e Pesquisas Educacionais Anísio Teixeira - INEP. Resultados Saeb/Prova Brasil 2011. Visualizada através de <http://download.inep.gov.br/educacao_basica/prova_brasil_saeb/resultados/2012/Saeb_2011_ primeiros_resultados_site_Inep.pdf > Acesso em: 15/06/2013.

MAEHR, M. L.; MEYER, H. A. Understanding Motivation and Schooling: Where We've Been, Where We Are, and Where We Need to Go. Educational Psychology Review, v. 9, n. 4, 1997. Visualizada através de <http://moodle.stoa.usp.br/mod/resource/view.php?id=2662. Acesso em: 16/05/2013.

MOREIRA, M. A. Teorias de aprendizagem. Sao Paulo, SP: EPU, 1999.

MOSQUERA, J.J. Mouriño. Psicodinâmica do aprender. Porto Alegre, Sulina, 1977. 
PENNA, A. G. Aprendizagem e motivação. Rio de Janeiro: Zahar Editores, 1979.

PIAGET, J. Seis estudos de psicologia. Tradução Maria A M D Amorim e Paulo Sérgio L Silva. RJ: Forense Universitaria, 1999.

Psicologia da inteligência . Rio de Janeiro: Editora Fundo de Cultura, 1967.

REVISTA DO SENAC - Publicação de divulgação do Serviço Nacional de Aprendizagem Comercial Departamento Nacional. Senac e Pronatec: parceria pela inclusão. Ano 63, jan/fev 2013 - no 715 